\title{
Impaired hematopoiesis in mice lacking the transcription factor Sp3
}

Pieter Fokko van Loo, Peter Bouwman, Kam-Wing Ling, Sabine Middendorp, Guntram Suske, Frank Grosveld, Elaine Dzierzak, Sjaak Philipsen, and Rudolf W. Hendriks

\begin{abstract}
As the zinc-finger transcription factor specificity protein $3(\mathrm{Sp} 3)$ has been implicated in the regulation of many hematopoietic-specific genes, we analyzed the role of Sp3 in hematopoiesis. At embryonic day 18.5 (E18.5), Sp3 ${ }^{-1-}$ mice exhibit a partial arrest of T-cell development in the thymus and B-cell numbers are reduced in liver and spleen. However, preB-cell proliferation and differentiation into immunoglobulin $\mathrm{M}$-positive $\left(\operatorname{lgM}^{+}\right)$B cells in vitro are not affected. At E14.5 and
\end{abstract}

E16.5, Sp3 ${ }^{-1-}$ mice exhibit a significant delay in the appearance of definitive erythrocytes in the blood, paralleled by a defect in the progression of differentiation of definitive erythroid cells in vitro. Perinatal death of the null mutants precludes the analysis of adult hematopoiesis in $S p 3^{-1-}$ mice. We therefore investigated the ability of E12.5 Sp3 ${ }^{-1-}$ liver cells to contribute to the hematopoietic compartment in an in vivo transplantation assay. $S p 3^{-1-}$ cells were able to repopulate the
B- and T-lymphoid compartment, albeit with reduced efficiency. In contrast, $\mathrm{Sp3}^{-1-}$ cells showed no significant engraftment in the erythroid and myeloid lineages. Thus, the absence of Sp3 results in cell-autonomous hematopoietic defects, affecting in particular the erythroid and myeloid cell lineages. (Blood. 2003;102:858-866)

(C) 2003 by The American Society of Hematology

\section{Introduction}

The transcription factor specificity protein 3 (Sp3) belongs to the $\mathrm{Sp} / \mathrm{X}$ Krüppel-like factor (XKLF) family of nuclear proteins that share a zinc-finger domain containing $3 \mathrm{C}_{2} \mathrm{H}_{2}$-type zinc fingers related to those found in the Drosophila melanogaster regulator protein Krüppel. ${ }^{1} \mathrm{Sp} 1, \mathrm{Sp} 3$, and $\mathrm{Sp} 4$ bind with equal affinity to the classical GC box and the related GT/CACC boxes present in many housekeeping and tissue-specific genes. Sp1 and Sp3 are widely expressed, whereas Sp4 shows a complex expression pattern but is most abundant in neuronal tissues. Sp factors not only are able to stimulate transcription from proximal promoters or from distal enhancers, ${ }^{2}$ but can also physically interact with other transcription factors, such as E2F-I, nuclear factor- $\mathrm{kB}$ (NF- $\mathrm{KB})$, and GATA-1. ${ }^{3-5}$ $\mathrm{Sp} 1$ and $\mathrm{Sp} 3$ can have additive or synergistic effects on gene activation, but $\mathrm{Sp} 3$ is also able to repress transcription driven by Sp1 or other transcription factors. . $^{6,7}$

The characterization of mutant mice has provided important information about the biologic function of the individual Sp/XKLF proteins. Yet only a limited number of target genes for the $\mathrm{Sp} / \mathrm{XKLF}$ family members have been identified to date. In particular, the G-rich sequences in the locus control region (LCR) of the $\beta$-globin cluster were identified as direct targets of Sp/XKLF transcription factors. Sp1, Sp3, basic KLF (BKLF), and erythroid KLF (EKLF) are all present in erythroid cells, but only EKLF appears to be essential for $\beta$-globin expression and activation of the LCR. ${ }^{8-10}$ EKLF-deficient mice die in utero owing to a severe anemia caused by severely reduced $\beta$-globin expression. ${ }^{8,9}$ BKLF has a role in myeloid proliferation, as $B K L F^{-1-}$ mice have increased numbers of myeloid cells, which also show increased proliferation rates in vitro. ${ }^{11}$ Lung KLF (LKLF) is required for

From the Department of Cell Biology and the Department of Immunology, Erasmus MC, Rotterdam, The Netherlands; and the Institut für Molekularbiologie und Tumorforschung Philipps-Universität Marburg, Germany.

Submitted June 21, 2002; accepted February 25, 2003. Prepublished online as Blood First Edition Paper, April 3, 2003; DOI 10.1182/blood-2002-06-1848.

Supported by the Netherlands Organization for Scientific Research (NWO) (R.W.H., F.G., and S.P.) and the Deutsche Forschungsgemeinschaft (DFG) (G.S.). blood vessel development and has been implicated in the maintenance of mature T cells. ${ }^{12,13} \mathrm{Sp} 1$-null embryos are severely retarded in growth and die after day 10 of embryonic development (E10). As $S \mathrm{pl}^{-1-}$ cells did not contribute to any tissue of newborn chimeric animals, the Sp1 deficiency causes a cell-autonomous defect. ${ }^{14}$ $S p 3^{-1-}$ embryos are also growth retarded, resulting in prenatal lethality or death at birth, apparently owing to respiratory failure. ${ }^{15}$ The cause for the observed breathing defect remains obscure, as only minor morphologic alterations were observed in the lung and surfactant protein expression was normal. Furthermore, $S p 3^{-1-}$ mice show a pronounced defect in late tooth formation associated with a deficiency of ameloblast-specific transcripts, ${ }^{15}$ and impaired skeletal ossification, reflected by significantly diminished expression of the osteoblast-specific marker gene osteocalcin. ${ }^{16}$ The phenotype of $S p 4^{-1-}$ mice differs from those described for $S p 1^{-1-}$ and $S p 3^{-1-}$ mice, as they develop until birth without obvious abnormalities. After birth, two thirds of the knockout mice die within 4 weeks as a consequence of cardiac arythmia. ${ }^{17}$ Surviving mice are growth retarded, and male $S p 4^{-1-}$ mice do not breed. ${ }^{18}$

$\mathrm{Sp} 3$ was originally cloned in a search for Sp1-related factors that bind to a GT box required for the transactivation of a T-cell receptor (TCR) $\mathrm{V}_{\alpha}$ gene segment. ${ }^{19}$ Since then, numerous functional binding sites for $\mathrm{Sp}$ factors have been identified that implicate Sp factors in the regulation of T- and B-cell development, for example, in TCR and immunoglobulin-enhancer regions, the promoter that directs germ line transcription of $D \beta J \beta$ gene segments in precursor $\mathrm{T}$ lymphocytes, the interleukin-2 receptor (IL-2R) $\beta$-chain, and promoter regions of genes encoding the B-cell receptor signaling molecules immunoglobulin- $\alpha$ (Ig- $\alpha$ ), marked "advertisement" in accordance with 18 U.S.C. section 1734.

(C) 2003 by The American Society of Hematology 
Ig- $\beta$, and Bruton tyrosine kinase (Btk). ${ }^{2,19-25}$ In addition, Sp1/Sp3 sites have been shown to be involved in the regulation of macrophage colony-stimulating factor (M-CSF), which is essential for myeloid development. ${ }^{26}$

Therefore, the presence of Sp-binding sites in various regulatory regions of lymphoid-, erythroid-, and myeloid-specific genes prompted us to investigate hematopoietic development in Sp3deficient mice. As the $S p 3$ gene was disrupted by targeted insertion of a lac $Z$ reporter gene, ${ }^{15}$ we could quantify the $\mathrm{Sp} 3$ expression profile in the individual hematopoietic compartments by analysis of $\beta$-galactosidase activity. When we compared $S p 3^{-1-}$ embryos with wild-type littermates, we identified a significant delay in the formation of $\mathrm{T}$ and B lymphocytes at E18.5, and erythrocytes at E14.5 and E16.5. Moreover, Sp3-deficient E12.5 liver cells did not significantly repopulate the erythroid or myeloid cell lineages in an in vivo transplantation assay. Our findings indicate that the lack of Sp3 intrinsically affects hematopoietic development, especially of the erythroid and myeloid lineages.

\section{Materials and methods}

\section{Mice}

Embryos were derived from timed matings of $\mathrm{Sp}^{+/-} \times \mathrm{Sp}^{+/-}$mice. ${ }^{15}$ Genotyping was performed by polymerase chain reaction (PCR), with the use of the following 3 primers: a sense primer in the $S p 3$ gene amplifying the wild-type allele ( $5^{\prime}$-GCGTGCAAGCCAGTGGTC- $\left.3^{\prime}\right)$; a sense primer in the Neo gene amplifying the knockout allele (5'-AGCGCATCGCCTTCTATCG- $\left.3^{\prime}\right)$; and a common antisense primer in the $S p 3$ gene $\left(5^{\prime}\right.$ GGACGATTCTATGCCTCC-3'). PCR conditions were $94^{\circ} \mathrm{C}$ for 1 minute, $60^{\circ} \mathrm{C}$ for 1 minute, and $72^{\circ} \mathrm{C}$ for 1 minute for 30 cycles.

\section{Flow cytometric analysis}

The preparation of single-cell suspensions, determination of $\beta$-galactosidase activity by means of fluorescein-di- $\beta$-D-galactopyranoside (FDG), antibody incubations, and 3- or 4-color cytometry have been described previously. ${ }^{27}$ The following monoclonal antibodies were obtained from Pharmingen (San Diego, CA): fluorescein isothiocyanate (FITC)conjugated anti-B220/RA3-6B2 and anti-CD3; phycoerythrin (PE)conjugated anti-CD4, anti-CD5, anti-CD11b/macrophage 1 (Mac-1), antiCD19, anti-C23, anti-CD25/IL-2R (clone 3C), anti-CD43/Ser7, antiCD45RB, anti-CD69, anti-natural killer cell 1.1 (anti-NK1.1), and antiTer119; biotinylated anti-IgM, anti-CD4, and anti-CD8; CyChromeconjugated anti-CD8, anti-CD44, and anti-B220/RA-6B2; peridinin chlorophyll protein (Per-CP)-conjugated anti-CD11b/Mac1; and allophycocyanin (APC)-conjugated anti-CD3, anti-CD5, and anti-CD4. Southern Biotechnology Associates (Birmingham, AL) supplied PE-conjugated antiIgD. Anti-CD8/53-6.7, anti-CD21, anti-Gr-1/RB6-8C5, and ER-MP20/Ly6$\mathrm{C}^{28}$ were purified monoclonal antibodies conjugated to biotin according to standard procedures. Secondary antibodies used were Tricolor- or PEconjugated streptavidin (Caltag Laboratories, Burlingame, CA) or CyChrome- or APC-conjugated streptavidin (Pharmingen).

\section{In vitro culture of fetal liver-derived B and erythroid cells}

Primary pre-B-cell cultures were essentially performed as described previously. ${ }^{29,30}$ In brief, fetal liver cells were cultured in Iscove modified Dulbecco medium (IMDM) medium, supplemented with $10 \%$ heatinactivated fetal calf serum (FCS) at 2 to $3 \times 10^{6}$ cells per well in 24-well plates in the presence of $100 \mathrm{U} / \mathrm{mL}$ recombinant IL-7 (R\&D Systems, Minneapolis, MN). After 5 days of culture, cells were harvested and recultured on S17 stromal cells with or without $100 \mathrm{U} / \mathrm{mL}$ IL-7 for 48 hours.

For suspension culture assays, fetal livers were collected from embryos and disaggregated to single-cell suspensions; then, $5 \times 10^{4}$ cells were placed in 20- $\mu \mathrm{L}$ drops suspended on the lid of a Petri dish (Lindeboom et al, manuscript in preparation).

\section{Colony assays}

Colony assays were performed essentially as described. ${ }^{31,32}$ Fetal livers were disaggregated into single cells by pippeting and were plated out in methyl cellulose containing $1 \mathrm{U} / \mathrm{mL}$ erythropoietin (Epo) at a cell density of $15 \times 10^{5}$ and $3 \times 10^{5} / \mathrm{mL}$ for erythroid colony-forming units (CFU-Es) and erythroid burst-forming units (BFU-Es), respectively. The appearance of colonies was scored after 3 (CFU-Es) and 9 (BFU-Es) days.

\section{Analysis of peripheral blood}

E12.5, E14.5, and E16.5 embryos were dissected and bled on a dish to collect the fetal blood in $1 \times$ phosphate-buffered saline (PBS) containing $0.5 \mathrm{mM}$ EDTA (ethylenediaminetetraacetic acid). Cell size distributions were determined on a Casy1 instrument (Schärfe System, Reutlingen, Germany). Aliquots of the blood were loaded on a cytofunnel and spun at $1000 \mathrm{rpm}$ for 2 minutes on microscope slides. The preparations were left to air dry and stained with a combined histologic and neutral benzidinestaining procedure. ${ }^{33}$

\section{In vivo transplantation assay}

Fetal liver cell suspensions, prepared by treatment with $0.125 \% \mathrm{wt} / \mathrm{vol}$ collagenase for 1 hour at $37^{\circ} \mathrm{C}$ in PBS with $10 \%$ FCS, were transferred intravenously into 8- to 10 -week-old C57BL/6 female mice, which were exposed to a split dose of $9 \mathrm{~Gy}$ at a 3-hour interval by a ${ }^{137} \mathrm{Cs}$ source. To provide short-term survival, $2 \times 10^{5} \mathrm{C} 57 \mathrm{BL} / 6$ female splenocytes were coinjected. Mice were maintained in filter-top cages and received $0.16 \%$ neomycin-supplemented water. ${ }^{34,35}$ Donor tissues were examined for $\mathrm{Sp} 3$ genotype and sex (Y chromosome) by DNA PCR of somite tissue or body remnants from dissected embryos. Donor-derived engraftment was examined by semiquantitative PCR of DNA from peripheral blood with the use of $S p 3$ wild-type and mutant-specific primers, or primers for the male-specific YMT2 gene. $^{34,35}$

\section{Results}

\section{Expression of the lacZ knock-in reporter gene during T-cell development in the thymus}

As a role for $\mathrm{Sp} 3$ in particular hematopoietic cell lineages may be indicated by modulations of the $S p 3$ gene expression, we took advantage of the presence of a lac $Z$ reporter gene in the targeted allele of $S p 3^{+/-}$heterozygous mice, which was placed under direct Sp3 transcriptional control ${ }^{15}$ (Table 1; Figure 1). The expression of

Table 1. Expression of lacZ in hematopoietic lineages

in Sp3 $3^{+/-}$E18.5 embyros

\begin{tabular}{|c|c|}
\hline Organ and cell population & Fraction of lac $Z$ cells, $\%$ \\
\hline \multicolumn{2}{|l|}{ Liver } \\
\hline B220+ B-lineage cells & $92 \pm 1.4$ \\
\hline Ter119+ erythroid, large FSC & $75 \pm 2.4$ \\
\hline Ter119+ erythroid, small FSC & $45 \pm 3.4$ \\
\hline \multicolumn{2}{|l|}{ Spleen } \\
\hline $\mathrm{IgM}^{-} \mathrm{B}^{-20^{+}}$pre-B cells & $93 \pm 0.7$ \\
\hline $\operatorname{lgM}^{+} \mathrm{B} 220^{+} \mathrm{B}$ cells & $92 \pm 3.7$ \\
\hline Ter119+ erythroid, large FSC & $90 \pm 2.6$ \\
\hline Ter119+ erythroid, small FSC & $38 \pm 3.7$ \\
\hline \multicolumn{2}{|l|}{ Bone marrow } \\
\hline Ly-6C ${ }^{\text {med }}$ granulocyte precursors* & $72 \pm 3.8$ \\
\hline Ly-6Chigh monocyte precursors & $89 \pm 1.1$ \\
\hline
\end{tabular}

Data are presented as mean values \pm standard deviation $(\mathrm{SD}) ; \mathrm{n}=4$ FSC indicates forward scatter.

${ }^{*}$ See de Bruijn et al. ${ }^{28}$ 
A

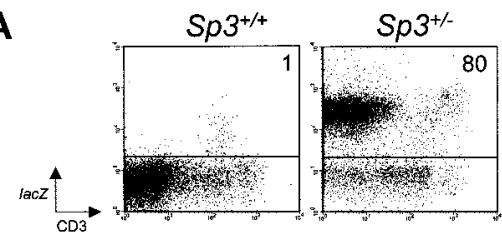

B

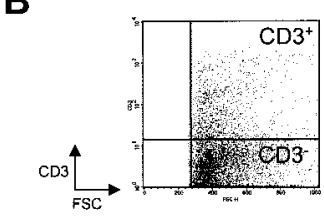

CD3 cells
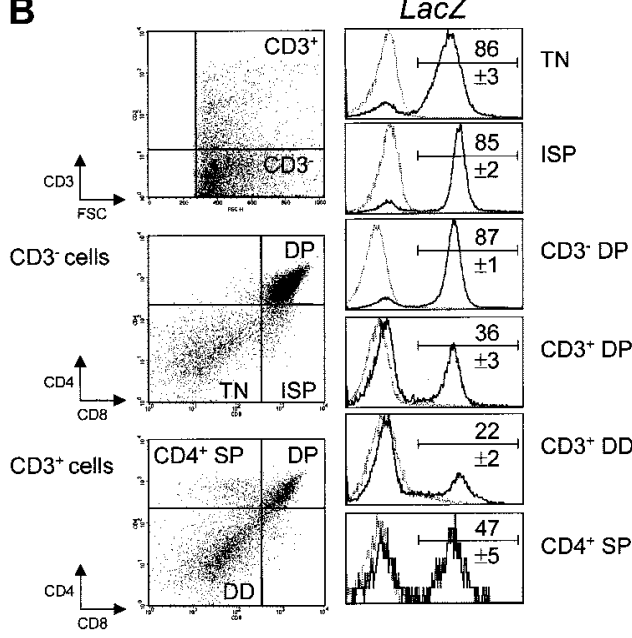

Figure 1. Analysis of lacZ expression in thymocytes from Sp3 $3^{+/-}$embryos by 4-color cytometry. Thymus cell suspensions were loaded with FDG substrate and subseqently stained for CD3, CD4, and CD8. (A) Total thymocytes were analyzed for CD3 expression and lacZ activity. (B) Cells were analyzed for CD3 expression; CD3 and $\mathrm{CD}^{+}$fractions were analyzed for CD4 and CD8; and the indicated subpopulations were gated and analyzed for lac $Z$ activity. The results are displayed as histograms of $\mathrm{Sp}^{+/-}$embryos (bold lines), together with those of wild-type embryos (dashed lines). The numbers are the proportions of lacZ-expressing cells (mean values $\pm S D, n=6)$. Background values in wild-type mice $(n=4)$ were below $1 \%$ in all fractions, except for the $\mathrm{CD}^{+}$double-dull (DD) fraction, in which $3 \% \pm 1 \%$ of the cells were $\mathrm{lacZ}^{+}$

Sp3-directed lac Z was analyzed in flow cytometry experiments, with the use of FDG as a fluorogenic $\beta$-galactosidase substrate in conjunction with antibodies specific for the individual hematopoietic cell lineages.

In E18.5 Sp3 $3^{+/-}$embryos, we found high levels of lacZ activity in the B-lymphoid and myeloid compartments. The differentiation of large into small Ter119+ erythroid cells was associated with a decrease of lac $Z$ activity (Table 1). In the thymus, we identified a modulated expression profile, characterized by a significant downregulation of lac $Z$ expression when differentiating $\mathrm{T}$ cells started to express the TCR/CD3 complex (Figure 1A). In the most immature population of $\mathrm{CD}^{-} \mathrm{CD}^{-}{ }^{-} \mathrm{CD} 8^{-}$triple-negative (TN) thymocytes, lac $Z$ expression was detected in more than $80 \%$ of the cells. Also the 4 subpopulations of these TN cells, as defined by differential CD44 and CD25 expression invariably showed greater than $80 \%$ lac $Z^{+}$cells (data not shown). High levels of lacZ activity were maintained in the next stages of T-cell development, that is, the $\mathrm{CD}^{-} \mathrm{CD}^{+}{ }^{+}$immature single-positive (ISP) cells, which have successfully rearranged their TCR $\beta$ locus, and the $\mathrm{CD} 3^{-} \mathrm{CD} 4^{+} \mathrm{CD} 8^{+}$ double-positive (DP) cells, which are in the process of TCR $\alpha$ gene rearrangement (Figure 1B). After successful TCR $\alpha$ rearrangement, a complete $\alpha \beta$ TCR is expressed on the cell surface, and subsequently a relatively small number of TCR $\alpha \beta$-bearing DP cells are selected for major histocompatibility complex (MHC) recognition and up-regulate surface expression of the TCR $\alpha \beta / C D 3$ complex during the process of positive selection. ${ }^{36}$ At this stage, $\mathrm{CD}^{+}{ }^{+} \mathrm{DP}$ cells down-regulate surface $\mathrm{CD} 4 / \mathrm{CD} 8$ coreceptor expression, to become $\mathrm{CD} 4{ }^{\text {low }}{ }^{\mathrm{CD}} 8^{\text {low }}$ double-dull (DD) cells. ${ }^{37}$ Remarkably, at the $\mathrm{CD}^{+}{ }^{+} \mathrm{CD} 4{ }^{+} \mathrm{CD} 8{ }^{+} \mathrm{DP}$ and $\mathrm{DD}$ cell stages, the propor- tion of lacZ-expressing cells was significantly down-regulated to approximately $20 \%$. When cells further differentiated into mature CD4 single-positive (SP) cells, the proportion of $\mathrm{lacZ}^{+}$cells increased to approximately 50\%. At E18.5, CD8 single-positive cells were not yet detectable in the thymus.

In summary, these analyses indicate that Sp3 is abundantly expressed in the various hematopoietic lineages. In contrast, during T-cell development, lac $Z$ expression is high in early $\mathrm{CD}^{-}$ precursor T-cell stages, specifically down-regulated during positive selection of TCR $\alpha \beta^{+}$DP T cells, and finally up-regulated in CD4 SP cells.

\section{Partial arrest of T-cell development at the DP stage in Sp3-deficient embryos}

At E18.5, Sp3 $3^{-1-}$ embryos are smaller (approximately 75\%) than their wild-type littermates. ${ }^{15}$ With this taken into consideration, the development of the thymus appeared to be relatively more affected, as $S p 3^{-1-}$ E18.5 embryos had a considerably smaller thymus, containing only approximately $30 \%$ of the cell numbers of wild-type littermates (Figure 2A). To analyze the effect of Sp3 expression on T-cell development in more detail, we determined the sizes of the individual T-cell precursor subpopulations in the thymus of $S p 3^{-/-}, S p 3^{+/-}$, and $S p 3^{+/+}$mice at E18.5 by flow cytometry (Figure 2B). These analyses revealed that in $S p 3^{+/-}$ embryos, the various T-cell precursor populations were present in near-normal abundance, except for the CD4 SP population, which was approximately $60 \%$ of normal size. In contrast, the absence of $\mathrm{Sp} 3$ resulted in a partial arrest of T-cell development, as the numbers of DP and CD4 SP cells in the $S p 3^{-1-}$ mice were reduced by a factor greater than 3 and greater than 7, respectively, when compared with wild-type littermates.

As these findings indicate that Sp3 deficiency affects T-cell development, particularly at the DP stage, we investigated $S p 3^{-1-}$ and $S p 3^{+/+}$DP thymocytes in more detail. We observed that $S p 3^{-1-}$ $\mathrm{CD}^{-}$DP cells had increased average forward scatter values, suggesting that a large proportion of the Sp3-deficient DP cells still have morphologic characteristics of the actively cycling ISP cells (Figure 2C). However, an increased proliferation rate of $S p 3^{-1-}$ cells at the DP cells seems unlikely, as the total size of the DP compartment in $\mathrm{Sp}^{-1-}$ mice is decreased. Rather, it suggests that the Sp3-deficient DP cells still bear hallmarks of the previous stage owing to a defect in developmental progression. It has been shown that upon MHC/TCR $\alpha \beta$ interaction, DP develop into DD cells, up-regulate expression of the TCR/CD3 complex, and start to express the very early activation antigen CD69 on the membrane. ${ }^{37}$ When we specifically analyzed DP and CD $4{ }^{\text {low }} \mathrm{CD} 88^{\text {low }} \mathrm{DD}$ cells, we found that in the absence of Sp3 the induction of CD3 and CD69 expression on the surface of DD cells was significantly reduced (Figure 2D).

In summary, we conclude that the $S p 3^{+/-}$and $S p 3^{-1-}$ embryos manifest a defect in thymocyte maturation at the DP cell stage. This arrest in differentiation coincides with the observed downregulation of lacZ expression during positive selection of $\operatorname{TCR} \alpha \beta^{+}$ DP T cells.

\section{Impaired B-cell development in Sp3-deficient embryos}

The absence of Sp3 also affected the B-cell system. E18.5 Sp3 $3^{-1-}$ livers were smaller in size and manifested a reduction of both total cellularity and the absolute numbers of $\mathrm{B} 220^{+}$B-lineage cells, when compared with livers from wild-type littermates (Figure 3A). Moreover, detailed flow cytometric analysis of liver and spleen 
A
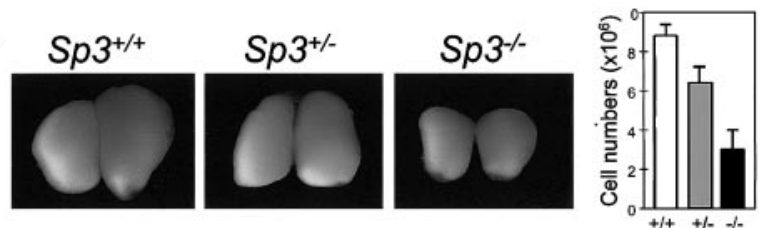

B

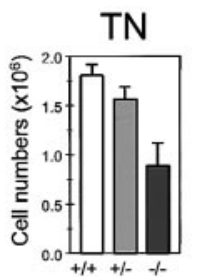

ISP
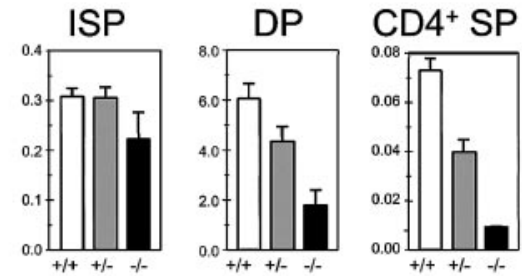

C

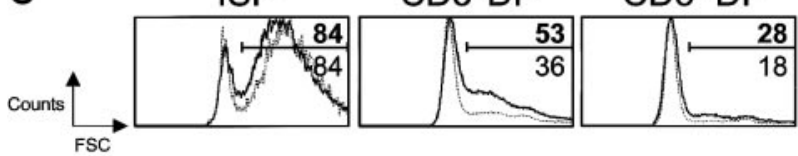

D

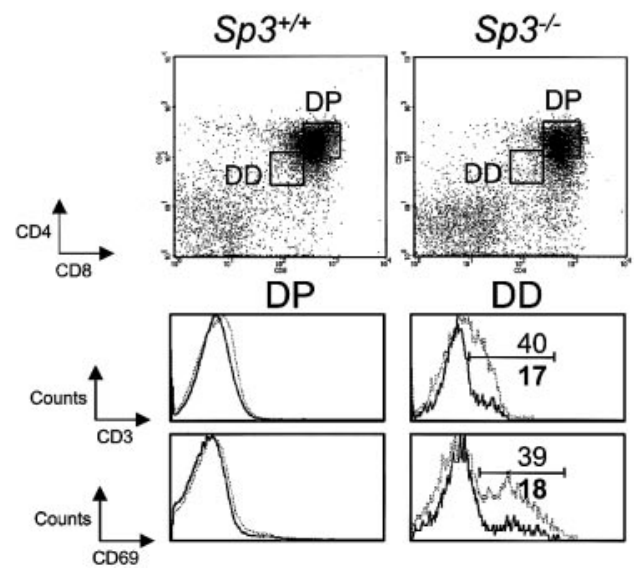

Figure 2. Impaired T-cell development in embryos lacking Sp3. (A) Thymi of E18.5 embryos of one litter (left) and total numbers of thymocytes (right) of the indicated genotypes. (B) Absolute numbers of thymocytes within the indicated thymic subpopulations, as determined by flow cytometry. $\mathrm{Tn}=\mathrm{CD} 3^{-} \mathrm{CD} 4^{-} \mathrm{CD} 8^{-}$; ISP $=$ $\mathrm{CD}^{-}{ }^{-} \mathrm{CD} 8{ }^{+} ; \mathrm{DP}=\mathrm{CD}^{+}{ }^{+} \mathrm{CD} 8{ }^{+}$; and $\mathrm{CD} 4 \mathrm{SP}=\mathrm{CD}^{+}{ }^{+} \mathrm{CD} 4{ }^{+} \mathrm{CD} 8^{-}$. (C) FSC character istics of the indicated thymus subpopulations. Cells were analyzed for the expression of CD3, CD4, and CD8, and FSC characteristics are displayed as histogram overlays of $\mathrm{Sp}^{-1-}$ (bold lines) and $\mathrm{Sp}^{+/+}$(dashed lines) embyros. (D) CD3 and CD69 expression in $\mathrm{DP}\left(\mathrm{CD} 4^{+} \mathrm{CD} 8^{+}\right)$and $\mathrm{DD}\left(\mathrm{CD} 4^{\text {low }} \mathrm{CD} 8^{\text {low }}\right)$ thymocytes. Thymus cell suspensions were gated for CD4 and CD8, and results are displayed as histogram overlays for CD3 and $\mathrm{CD} 69$ of $\mathrm{Sp}^{-/-}$(bold lines) and $\mathrm{Sp}^{+/+}$(dashed lines) embyros. Data shown are from 2 to 26 embryos in each group.

demonstrated an approximately 2-fold lower percentage of surface $\mathrm{IgM}^{-} \mathrm{B}$-cell precursors and an approximately 5-fold lower percentage of $\operatorname{IgM}^{+}$B cells than normally found at this age (Figure 3B). Intermediate values were found for $S p 3^{+/-}$mice, indicating an $S p 3$ gene dosage effect.

To investigate whether Sp3-deficient pre-B cells have an intrinsic defect in proliferative expansion or differentiation into $\mathrm{Ig}^{+}$ $\mathrm{B}$ cells, we performed in vitro IL-7-driven fetal liver pre-B-cell cultures. E18.5 fetal liver cells were cultured in the presence of 100 $\mathrm{U} / \mathrm{mL}$ IL-7, thereby specifically inducing proliferation of cytoplasmic Ig $\mu$ heavy-chain-positive pre-B cells. ${ }^{29}$ After 5 days of culturing, comparable numbers of $\mathrm{B}_{2} 20^{+} \mathrm{IgM}^{-}$pre-B cells were generated in $\mathrm{Sp}^{+/+}, \mathrm{Sp}^{+/-}$, and $\mathrm{Sp}^{-1-}$ fetal liver cultures. Subsequently, IL-7 was removed from the medium, and the cells were placed on S17 stromal cells for 48 hours to allow further differentiation. Flow cytometric analysis demonstrated that $S p 3^{-1-}$ pre-B cells differentiated normally into surface $\operatorname{IgM}^{+}$immature B cells upon IL-7 withdrawal. Furthermore, $S p 3^{-1-}$ B cells were able to differentiate into mature $\operatorname{IgM}^{+} \operatorname{IgD}^{+}$B cells, although apparently with a reduced efficiency, as lower levels of surface $\mathrm{IgD}$ expression were observed in $\mathrm{Sp}^{-1-}$ cultures (Figure 3C).

Taken together, these results indicate that in the absence of Sp3, B-cell development was impaired, as the numbers of (pre-)B cells in the liver and spleen of $S p 3^{-1-}$ embryos did not reach the levels of normal embryos. The IL-7-driven fetal liver culture experiments show that the proliferative capacity of $S p 3^{-1-}$ pre-B cells and their developmental progression into $\operatorname{IgM}^{+}$immature $\mathrm{B}$ cells in vitro are normal.

\section{The formation of definitive erythrocytes is delayed in Sp3-deficient embryos}

To study the effect of the absence of $\mathrm{Sp} 3$ on erythropoiesis, the number and the size of erythrocytes were analyzed in E12.5, E14.5, and E16.5 embryos (Figure 4A). Blood of wild-type embryos contained predominantly large primitive erythroid cells at E12.5, mainly small definitive erythrocytes at E14.5, and almost exclusively small definitive erythrocytes at E16.5, as described previously. ${ }^{38}$ In contrast, in E14.5 Sp3 $3^{-1-}$ blood, the majority of red cells were large primitive nucleated erythrocytes. A significant fraction

A
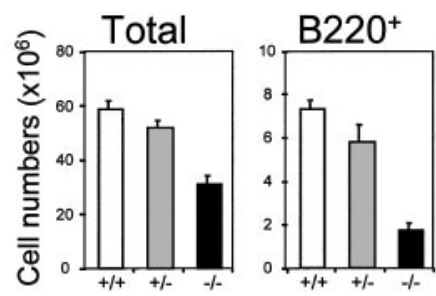

B

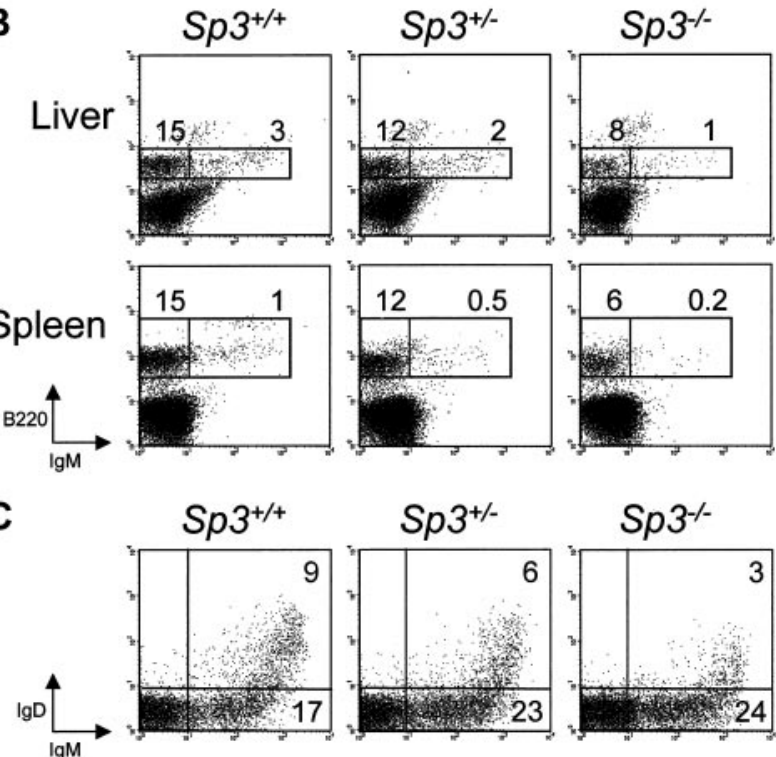

Figure 3. Impaired B-cell development in embryos lacking Sp3. (A) Numbers of total cells and $\mathrm{B} 220^{+}$cells in E18.5 liver of the indicated embryos, as determined by flow cytometry. (B) Flow cytometric analyses of the liver and spleen of the individua embryos. Single-cell supsensions were stained with B220 and IgM. Results are displayed as dot plots of lymphocyte gate cells; percentages of cells within the indicated gates are given. $(C)$ Developmental progression of $B$-lineage cells in vitro. Total BM cells were cultured in the presence of IL-7 for 5 days, and recultured on S17 stromal cells in the absence of IL-7 to induce the formation of mature $\operatorname{lgM}^{+} \operatorname{lgD}{ }^{+} \mathrm{B}$ cells. Cultured cells were stained for B220, IgM, and IgD. Results are displayed as B220 versus IgD dot plots. Data shown are from 4 to 15 embryos examined in each group. 
A
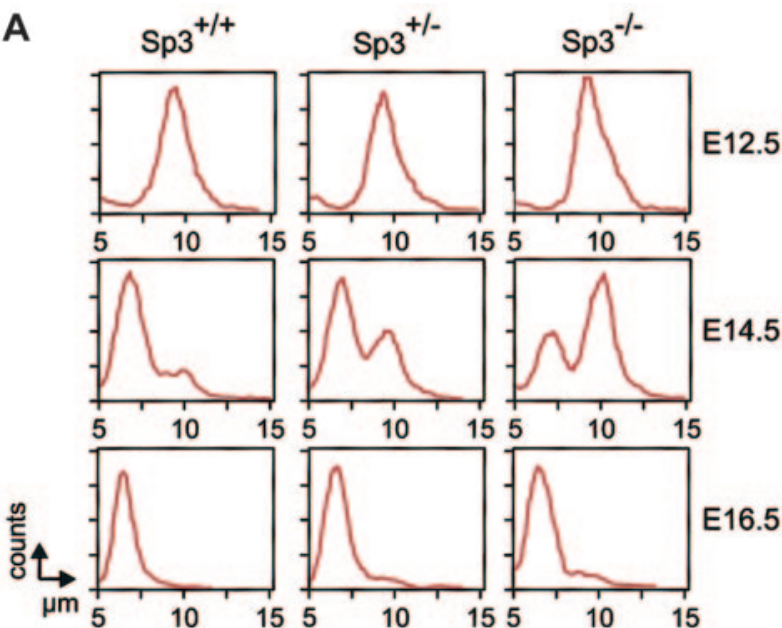

B
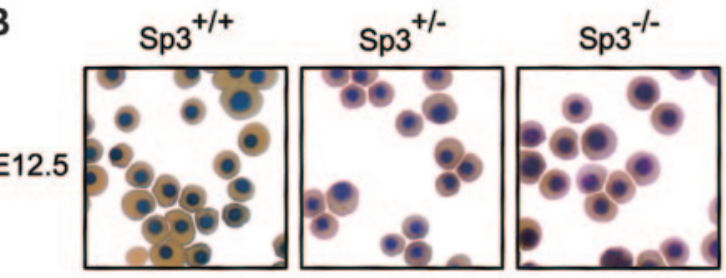

E12.5
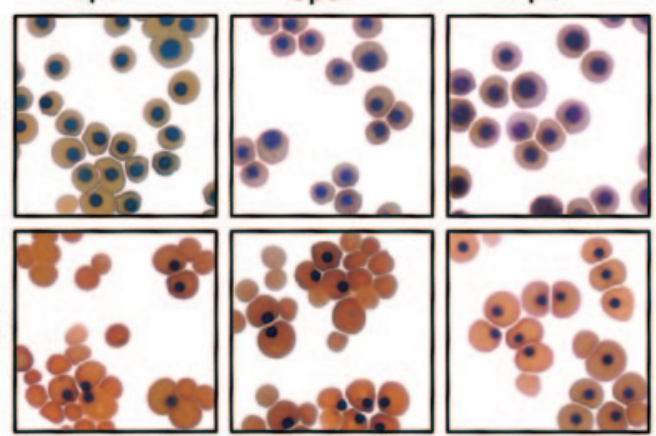

E14.5

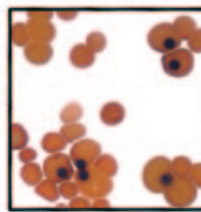

E16.5
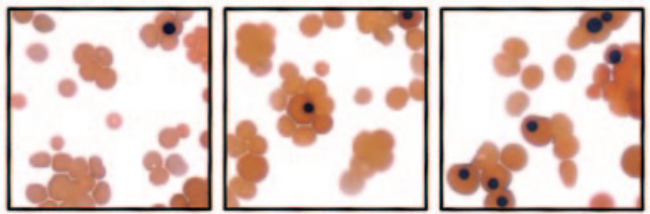

Figure 4. Delayed definitive erythropoiesis in Sp3-deficient embryos. (A) Analysis of the size distribution of circulating erythrocytes at different days of gestation. Yolk sac-derived erythrocytes (primitive) remain nucleated and have a diameter of approximately $10 \mu \mathrm{m}$. Fetal liver-derived erythrocytes (definitive) are enucleated and have a diameter of approximately $7 \mu \mathrm{m}$. Appearance of definitive erythroytes in the circulation is delayed in $S p 3^{-1-}$ embryos. (B) Cytospins were prepared from blood isolated from the indicated embryos and were stained with a combination of neutral benzidine and histologic dyes. ${ }^{33}$ Nucleated primitive erythroytes are clearly distinguished from enucleated definitive erythrocytes; both cell types have a normal morphologic appearance in $\mathrm{Sp}^{-1-}$ embryos.

of these primitive erythrocytes was still present at E16.5. As shown in Figure 4A, a delay in the formation of small definitive erythrocytes was also found in $\mathrm{Sp}^{+/-}$blood, but the phenotype was much less striking. These findings were confirmed in cytospin analyses, where, particularly at E14.5, increased proportions of nucleated primitive erythroid cells were detected in the blood from $S p 3^{-1-}$ embryos and, to a lesser extent, also in $\mathrm{Sp}^{+/-}$embryos (Figure 4B).

\section{Sp3-deficient erythroid cells display a cell-autonomous differentiation defect}

The observed delay in the appearance of circulating definitive erythrocytes could originate either from a delay in the colonization of the fetal liver by hematopoietic stem cells (HSCs) from the intraembryonic aorta-mesonephros-gonad (AGM) region ${ }^{35}$ and the yolk sac or from an intrinsic defect in the developmental progression of definitive erythrocytes. To distinguish between these 2 possibilities, the numbers of the erythroid progenitors erythroid BFU-Es and CFU-Es were determined in the liver of $\mathrm{Sp}^{+/+}$, $\mathrm{Sp}^{+/-}$, and $\mathrm{Sp}^{-1-}$ embryos at E12.5 and E14.5. The numbers of BFU-Es and CFU-Es per fetal liver were reduced approximately 3-fold in $\mathrm{Sp}^{-1-}$ fetal livers (Figure 5A). However, when the values were corrected for the cellularity of the fetal livers, the ratios of BFU-Es and CFU-Es were comparable in the 3 groups of embryos (Figure 5B). These findings indicate that, despite the reduced cellularity, the architecture of the hematopoietic compartment of the $S p 3^{-1-}$ fetal livers is normal, excluding a critical role for Sp3 in the colonization of the liver with HSCs. We therefore conclude that the observed delay in the formation of definitive erythrocytes most likely results from an intrinsic developmental defect of definitive erythroid cells.

To study the effect of Sp3 on the developmental progression of definitive erythroid cells in detail, E14.5 fetal liver cells were grown for 3 days in a suspension culture system. Since erythroid precursors are taken out of their embryonic microenvironment and cultured under specific conditions for further differentiation, cellautonomous defects in erythroid differentiation can be identified in this assay. ${ }^{32}$ After 2 days of culture, $45 \%$ of the cells in the $S p 3^{+/+}$ cultures were mature definitive erythrocytes, as compared with
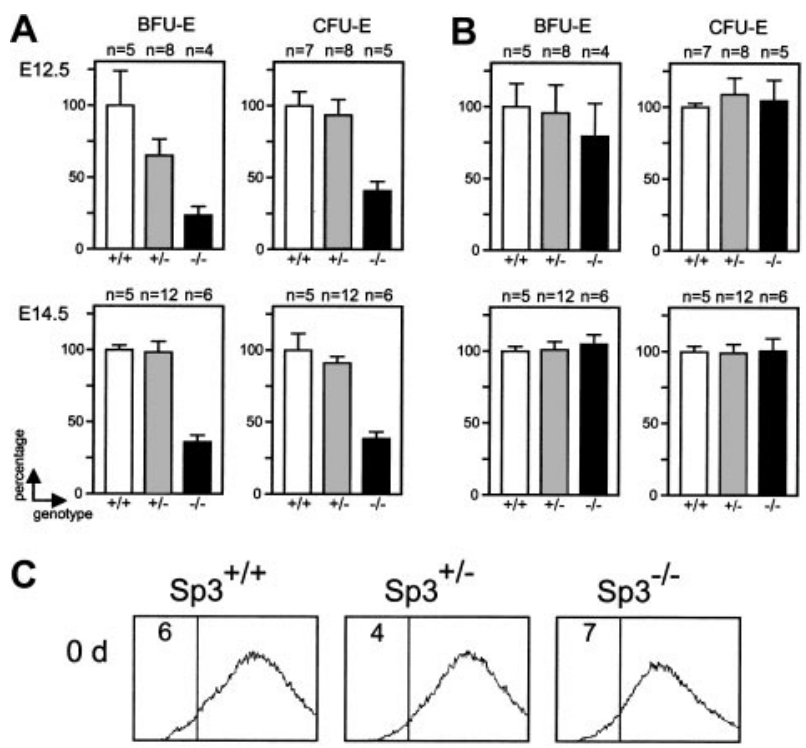

$2 d$
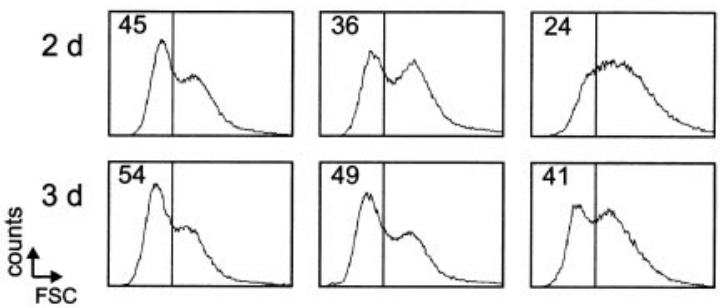

Figure 5. Sp3-deficient erythroid cells display a cell-autonomous differentiation defect. (A) The number of BFU-Es and CFU-Es per E12.5 and E14.5 fetal liver was determined for embryos with the indicated genotypes and gestational ages. The values in wild-type embryos were set at $100 \%$. (B) Abundance of BFU-Es and CFU-Es in E12.5 and E14.5 Sp3-deficient embryos corrected for the cellularity of fetal livers. Wild-type values were set at $100 \%$. (C) Fluorescence-activated cell sorter (FACS) analysis of fetal liver cells that were allowed to differentiate in vitro during 0,2 , and 3 days, using the suspension culture system. As the cells progress through maturation, they become smaller. Enucleated cells with small FSC values (lower than 360 , as indicated) appear during culture at days 2 and 3 . 
only $36 \%$ and $24 \%$ in $S p 3^{+/-}$and $S p 3^{-1-}$ cultures, respectively (Figure 5C). On the third day of culturing, the differences between the 3 groups became less pronounced, but were still significant (Figure 5C).

In summary, these experiments show that Sp3-deficient erythroid cells display a cell-autonomous differentiation defect in vitro. This might explain the delay in the formation of circulating definitive erythrocytes observed in vivo in $S p 3^{-1-}$ embryos and, to a lesser extent, in $S p 3^{+/-}$embryos.

\section{Sp3-deficient fetal liver cells show severely reduced in vivo hematopoietic repopulation potential}

The perinatal death of the $S p 3^{-1-}$ embryos precluded the analysis of adult hematopoiesis in the absence of Sp3. As we observed mild hematopoietic defects in Sp3-heterozygous embryos, we analyzed $S p 3^{+/-}$mice at 8 weeks of age. However, when we compared the lymphoid, myeloid, and erythroid compartments of $\mathrm{Sp}^{+/-}$and $S p 3^{+/+}$mice by flow cytometry, we did not observe any significant differences (data not shown).

To further define the role of Sp3 in the differentiation of the various hematopoietic cell lineages, we investigated the ability of $S p 3^{-1-}$ fetal liver hematopoietic stem cells and progenitors to contribute to the lymphoid, myeloid, and erythroid lineages in an in vivo transplantation assay. ${ }^{35}$ We transplanted E12.5 liver cells from $S p 3^{+/+}, S p^{3^{+/-}}$, and $S p 3^{-1-}$ embryos into irradiated adult female recipients. To correct for the differences in liver cellularity between the 3 genotypes, equal amounts of total liver cells were injected (approximately $2 \times 10^{5}$ cells). A limiting dose of syngeneic splenic cells was coinjected to aid the recipients in short-term survival following irradiation.

At 4 weeks after transplantation, recipient peripheral blood DNA was tested by PCR for the presence of the donor genetic marker, either the $S p 3$ mutant allele for the $S p 3^{+/-}$and $S p 3^{-1-}$ embryos, or the Y chromosome-specific marker YMT2 for the $\mathrm{Sp}^{+/+}$embryos. The donor-derived genetic marker was detected to high levels (greater than 10\%), ${ }^{35}$ in all mice that received $S p 3^{+1+}$ cells $(\mathrm{n}=4)$ or $S p 3^{+1-}$ cells $(\mathrm{n}=11)$. The Sp3 mutant marker was also detected in 6 of 7 recipients receiving $S p 3^{-1-}$ fetal liver cells.

At 6 weeks after transplantation, we examined the extent of multilineage repopulation in mice receiving transplants of $S p 3^{+/-}$ and $S p 3^{-1-}$ fetal liver cells $(\mathrm{n}=11$ and $\mathrm{n}=7$, respectively) by flow cytometric analysis of peripheral blood leukocytes. The contribution of donor cells to individual hematopoietic cell lineages was quantified by calculating the percentage of lacZ-expressing cells within the following subpopulations: $\mathrm{B} 220^{+} \operatorname{IgM}^{+/ \text {low }}$ $\mathrm{IgD}^{+/ \text {low }} \mathrm{B}$ cells, $\mathrm{CD}^{+}{ }^{+}$or $\mathrm{CD}^{+} \mathrm{T}$ cells, NK1.1 ${ }^{+} \mathrm{NK}$ cells, Mac- $1^{+} \mathrm{Gr}-1^{+}$granulocytes, and $\mathrm{Mac}-1^{+} \mathrm{Gr}-1^{-}$monocytes (Figure 6). Although the percentages of engraftment varied between individual mice and between cell lineages, $S p 3^{+/-}$cells were able to repopulate both lymphoid (B, T, and NK cells) and myeloid lineages (granulocytes and monocytes) in 8 of 11 recipients. In contrast, repopulation by $S p 3^{-1-}$ cells appeared to be restricted to the B-cell lineage ( 5 of 7 recipients). In those mice that showed repopulation of the B-cell lineage with $S p 3^{-1-}$ cells, the proportion of lac $^{+}$cells was on average lower, when compared with the $\mathrm{Sp}^{+/-}$group of mice. Only one mouse showed engraftment of $\mathrm{Sp}^{-1-}$ cells in the populations of $\mathrm{CD}^{+}$and $\mathrm{CD}^{+} \mathrm{T}$ cells, NK cells, granulocytes, and monocytes, but again the percentages of lac $Z^{+}$cells within these cell populations were low and did not exceed $20 \%$.

In summary, from these analyses, we conclude that $S p 3^{-1-}$ fetal liver cells have a reproducible deficiency in short-term repopula-

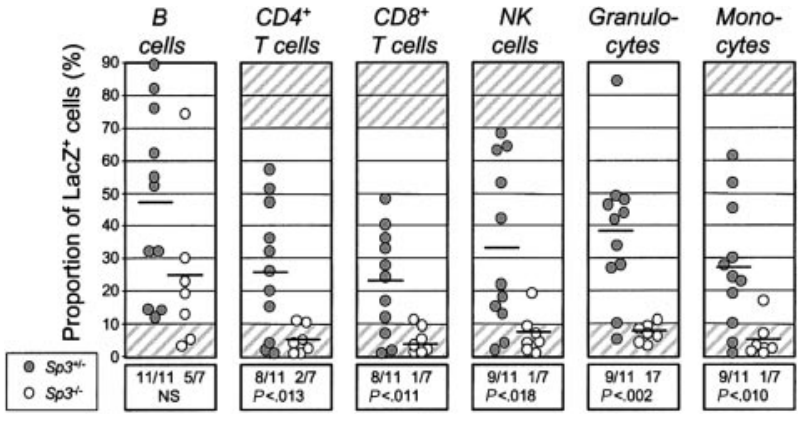

Figure 6. E12.5 Sp3-deficient fetal liver cells show reduced in vivo hematopoietic reconstitution. Analysis of the peripheral blood for lacZ-expressing cells at 6 weeks after transplantation in the indicated cell lineages in peripheral blood from mice that received $\mathrm{Sp}^{+/-}(\bullet)$ or $S p 3^{-/-}(\bigcirc)$ fetal liver cells. The mean number of injected cells per recipient was $2.6 \times 10^{5}(0.41 \pm 0.17$ embryo equivalents) for $S p 3^{+1-}$ fetal liver cells and $2.1 \times 10^{5}\left(0.58 \pm 0.13\right.$ embryo equivalents) for Sp3 ${ }^{-1}$ fetal liver cells. Fetal liver cells from 10 of $11 \mathrm{Sp3}^{+/-}$embryos and 4 of $7 \mathrm{Sp}^{+/-}$ embryos were transplanted into 2 mice, and in these cases the symbols show the average values in the 2 mice. In the other cases, the symbols represent the values in individual mice. Only recipients with more than $10 \%$ lac $Z^{+}$cells are considered positive. For comparison, the proportions of lacZ expression in 3-month-old Sp3 $3^{+1-}$ heterozygous mice are indicated (approximately $70 \%$ in T and NK cells, approximately $80 \%$ in monocytes, and approximately $90 \%$ in B cells and granulocytes, values that would therefore reflect $100 \%$ engraftment).

tion capacity of the hematopoietic system. In this respect, the presence of Sp3 appears to be less critical for reconstitution of the B-cell lineage.

\section{Sp3-deficient fetal liver cells display a specific defect in the ability to repopulate the erythroid and myeloid lineages}

The observed reduced repopulation capacity of $S p 3^{-1-}$ E12.5 fetal liver cells could either reflect a delayed development of mature lymphoid and myeloid cells from HSCs or multipotent progenitors or, alternatively, result from specific developmental arrests within these cell lineages.

To distinguish between these 2 possibilities, we analyzed, in more detail, the extent of hematopoietic repopulation in mice that received $S p 3^{+1-}(\mathrm{n}=3)$ and $S p 3^{-1-}(\mathrm{n}=3)$ fetal liver cells at 3 months after transplantation. The percentages of $\operatorname{lac}^{+}$cells were quantified within specific cell lineages present in hematopoietic tissues, including thymus, spleen, blood, bone marrow, and peritoneal cavity. At 3 months after transplantation, repopulation by $S p 3^{+1-}$ cells appeared to be almost complete (Figure 7), as in all analyzed mice the percentages of $l a c Z^{+}$cells within the lymphoid, myeloid, and erythroid cell lineages were close to the values found in control adult $S p 3^{+1-}$ mice. In contrast to our results at 6 weeks after transplantation, at 3 months after transplantation repopulation by $S p 3^{-1-}$ fetal liver cells was no longer confined to B cells, as the T-cell lineage also displayed significant repopulation by $S p 3^{-1-}$ donor cells: the fractions of $\mathrm{lacZ}^{+}$cells were $30 \% \pm 18 \%$ and $15 \% \pm 5 \%$ for $\mathrm{CD}^{+}$and $\mathrm{CD}^{+}$peripheral blood $\mathrm{T}$ cells, respectively (not shown). Figure 7 shows the analyses of the animal receiving transplants of $S p 3^{-1-}$ cells in which the highest percentages of $\mathrm{lacZ}^{+}$cells were observed. The thymocytes of the recipients grafted with $S p 3^{+1-}$ or $S p 3^{-1-}$ cells showed a similar pattern of modulated lacZ expression as was previously found in E18.5 thymus (Figures 1A,7A). Also in the spleen, $S p 3^{-l-}$ donor-derived cells contributed to the mature $\mathrm{CD}^{+}{ }^{+}$and $\mathrm{CD}^{+} \mathrm{T}$-cell populations. Moreover, $\mathrm{Sp}^{-1-} \mathrm{CD} 4^{+} \mathrm{T}$ cells were not different from $\mathrm{Sp} 3^{+1-}$ $\mathrm{CD}^{+}{ }^{+} \mathrm{T}$ cells in their ability to differentiate in vivo into antigenexperienced CD45RB ${ }^{\text {low }} \mathrm{T}$ cells ${ }^{39}$ (Figure $7 \mathrm{~B}$ ). $S p 3^{-1-}$ cells were less capable of repopulation in the NK-cell lineage (the proportions 


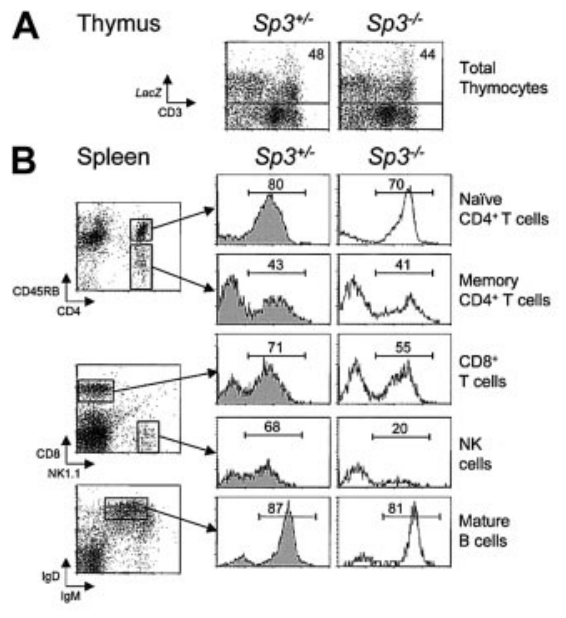

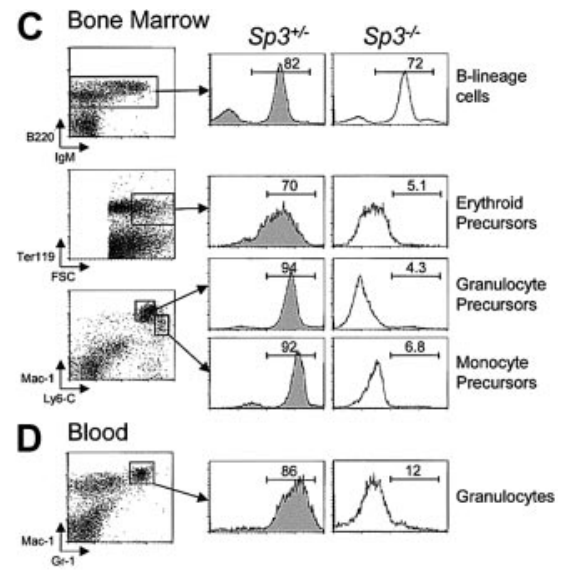

Figure 7. Absence of erythroid and myeloid repopulation by $\mathrm{Sp3}^{-1-}$ fetal liver cells in an in vivo transplantation assay. (A) Analysis for CD3 expression and lacZ activity in total thymocytes from $S p 3^{+1-}$ and $S p 3^{-1-}$ transplant recipients. (B-E) Total cell suspensions from spleen (panel B), bone marrow (panel C), periphera blood (panel D), and peritoneal cavity (panel E) were analyzed for lymphoid-, erythroid-, or myeloid-specific marker expression (left). In Sp3 $3^{+1-}$ and $\mathrm{Sp}^{-1-}$ transplant recipients, the indicated subpopulations were gated and analyzed for donor-derived lacZ expression (right). The results for transplanted $S p 3^{-1-}$ cells are from the animal in which the highest percentages of $\mathrm{lac}^{+}$cells were observed. LacZ expression data are displayed as histograms; the numbers are the proportions of lac $Z^{+}$ cells in which background values in wild-type mice were lower than $4 \%$.

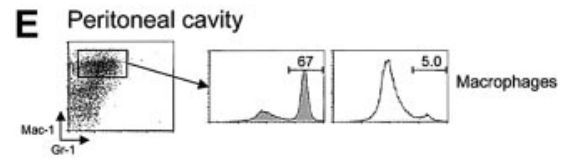

of $\mathrm{lacZ}^{+}$cells were $10 \% \pm 5 \%(\mathrm{n}=3)$ versus $56 \% \pm 19 \%$ in the group of mice with transplants of $\mathrm{Sp}^{+1-}$ cells). $S p 3^{-1-}$ cells contributed substantially to all peripheral B-cell subpopulations, including mature $\operatorname{IgM}^{\text {low }} \operatorname{IgD}{ }^{\text {high }}$ follicular B cells and CD21 high CD23- marginal zone cells in the spleen, and CD19high ${ }^{-} 5^{+}$B-1 peritoneal B cells (Figure 7B and data not shown), as well as to the B-cell compartment in the bone marrow (Figure 7C).

Even though the donor-derived $S p 3^{-1-}$ cells showed a substantial contribution to the lymphoid lineages, in the same recipient mice these cells did not repopulate the erythroid or myeloid lineages. Very low proportions of $\mathrm{lacZ}^{+}$cells were found in the large FSC Ter $119^{+}$erythroid precursors or the Ly6-C ${ }^{\text {med }}$ granulocyte and Ly6-Chigh monocyte precursors in the bone marrow (Figure 7C). Also mature granulocytes in the peripheral blood and mature macrophages in the peritoneum did not contain significant populations of $S p 3^{-1-} l a c Z^{+}$cells (Figure 7D-E).

From these findings, we conclude that at 3 months after transplantation, E12.5 Sp $3^{-1-}$ fetal liver cells can substantially repopulate the B- and T-cell lineages in lethally irradiated recipients. $S p 3^{-1-}$ cells were able to repopulate the NK-cell compartment, although the efficiency was very low. In strong contrast, the absence of $\mathrm{Sp} 3$ precluded significant repopulation of the erythroidand myeloid-cell lineages in the in vivo transplantation assay.

\section{Discussion}

In this report, we have studied the impact of the absence of the widely expressed transcription factor Sp3 on the developing hematopoietic system in the mouse. We demonstrate that lymphopoiesis, erythropoiesis, and myelopoiesis are all affected in Sp3 knockout embryos. Since these embryos are retarded in development, ${ }^{15}$ our observations might merely reflect the general delay in developmental progression. However, several lines of evidence argue against this hypothesis: (1) The finding of phenotypic alterations in erythroid cells in our in vitro cell culture experiments point toward an intrinsic defect in erythropoiesis in Sp3-null cells. (2) Even if the general developmental retardation is taken into account, the appearance of definitive erythrocytes in the circulation of Sp3-null embryos is delayed, and the B- and T-cell precursor populations are reduced in size. (3) The in vivo transplantation assay revealed differential effects of the absence of Sp3 for the individual cell lineages: delayed but almost complete repopulation of the B- and T-lymphoid compartment, and no significant repopulation in the erythroid and myeloid lineages. (4) The observed intermediate phenotype of $S p 3^{+/-}$embryos with regard to the appearance of definitive erythrocytes suggests a dosage effect. Effects of haploinsufficiency on hematopoiesis have been reported before, for instance, for EKLF ${ }^{40}$ and acute myeloid leukemia 1 (AML1), ${ }^{41}$ and are a strong indication for a direct role of the factor in the lineage affected. Therefore, our data collectively suggest that Sp3 deficiency has a specific impact on hematopoiesis.

\section{Sp/XKLF family members and erythropoiesis}

The hematopoietic defects of Sp3-null mice are subtle, and it appears unlikely that hampered hematopoiesis contributes significantly to the perinatal lethality. Severe anemia resulting from insufficient production of functional erythroid cells is the cause of embryonic lethality in the knockout of another Sp/XKLF family member, EKLF. In these mice, definitive erythropoiesis is defective owing to failure to activate expression of the adult $\beta$-globin genes. ${ }^{8} 9$ Surprisingly, the embryonic globins and the adult $\alpha$-globins are expressed normally in the EKLF knockouts. Many, if not all, erythroid-specific genes contain functionally important $\mathrm{Sp} /$ XKLF-binding sites in their promoters and other regulatory elements. Yet the transcription factors by which these genes are activated in vivo are still largely unknown, owing to the fact that the Sp/XKLF family comprises more than 20 different transcription factors. At least 5 of these (Sp1, Sp3, BKLF, EKLF, and fetal KLF $[F K L F])^{1}$ are expressed in erythroid cells. BKLF knockout mice do not appear to display an overt erythroid phenotype, but BKLF is known to be up-regulated in EKLF-null cells. ${ }^{8,11}$ This suggests that there might be overlapping functionality between BKLF and EKLF. Analysis of compound mutant mice would be required to clarify this issue. We have generated Spl knockout mice in our laboratory, but the early embryonic lethality precludes the analysis of definitive hematopoiesis in Sp1-deficient embryos. ${ }^{14}$ We have now created a conditional knockout allele of the Spl mutation. Preliminary data on erythroid-specific knockouts indicate that $\mathrm{Sp} 1$ is essential for primitive and definitive erythropoiesis (U. Jägle and S.P., unpublished results, December 2001). Our analysis of Sp4 
knockout mice has failed to demonstrate any hematopoietic defect, apart from the reduced cellularity of the thymus and spleen. ${ }^{18}$ This is thought to reflect a defect in the hormonal pituitary-gonadal axis, since it is known that such defects correlate with a reduced size of the thymus and delayed sexual maturation, as observed in Sp4 knockout mice. ${ }^{18}$

\section{Sp3 and embryonic/fetal erythropoiesis}

The analysis of erythropoiesis in Sp3-null mice presented here demonstrates a role for $\mathrm{Sp} 3$ in the transition from primitive to definitive erythropoiesis, and in the progression of erythroid maturation. Moreover, the lack of detectable repopulation of the erythroid compartment in the bone marrow by Sp3-deficient fetal liver cells in the transplantation experiments in vivo, together with the observed cell-autonomous differentiation defect in vitro, indicates that $\mathrm{Sp} 3$ function is essential for normal erythropoiesis. However, we did not find evidence for a critical role of Sp3 in the developmental timing of fetal- to adult-globin switching in vivo. In crosses of Sp3-deficient mice with transgenic mice containing the human globin cluster, ${ }^{42}$ the switch from $\gamma$ - to $\beta$-globin expression takes place between E11.5 and E13.5, irrespective of the Sp3 genotype (P.B. and S.P., unpublished results, September 2001).

\section{Sp3 and lymphopoiesis}

In the T-cell lineage, it is of interest to note that lac $Z$ staining indicates down-regulation of $\mathrm{Sp} 3$ expression upon transition of thymocytes from the DP to the SP cell stage. Of course, this may imply that $\mathrm{Sp} 3$ expression directly regulates genes that promote apoptosis of DP cells. However, Sp3 differs biochemically from the other $\mathrm{Sp}$ factors in that it contains an inhibitory domain. ${ }^{43} \mathrm{Sp} 3$ may therefore also function as a repressor of Sp-mediated transcription on some promoters. ${ }^{1,43}$ Thus, down-regulation of Sp3 at the DP stage may shift the balance of factors bound to GT boxes toward other Sp/XKLF family members. In this context, Sp3 could modulate the activity of the LKLF, which is induced at the progression from DP into SP and appears to play a critical role in programming the quiescent phenotype of SP thymocytes. ${ }^{13}$ However, Sp3 does not appear to be an essential regulator at this stage of T-cell development, as the observed partial arrest of T development at the DP stage in E18.5 Sp3 $3^{-1-}$ embryos was not paralleled by a defect at this stage in the mice in the transplantation group that received $S p 3^{-1-}$ fetal liver cells. The $l a c Z^{+}$DP and DD subpopulations in the mice receiving transplants of $S p 3^{+/-}$and $S p 3^{-1-}$ cells did not differ in FSC characteristics or the level of CD3 expression (data not shown). Also, the finding of similar contributions of $\mathrm{Sp}^{+/-}$and $\mathrm{Sp} 3^{-1-}$ cells to the CD45RB ${ }^{\text {low }}$ population of antigenexperienced $\mathrm{CD}^{+} \mathrm{T}$ cells in the spleen indicates that $S p 3^{-1-} \mathrm{T}$ cells can function normally and argues against a crucial role of Sp3 in positive selection in the thymus. Rather, the reduced size of the T-cell compartment in E18.5 embryos and the decreased capacity and kinetics to repopulate the T-cell lineage in the in vivo transplantation assay suggest a subtle defect in the expansion or generation of early T-cell progenitors. As the defects in the B-cell lineage are similar, it is attractive to speculate that $\mathrm{Sp} 3$ deficiency affects a common lymphoid progenitor. However, it is still unknown whether the common lymphoid progenitor that has been identified in adult mouse bone marrow also exists in fetal liver. ${ }^{44,45}$

\section{Sp3 and adult erythropoiesis/myelopoiesis}

The transplantation experiments demonstrate that $S p 3^{-1-}$ fetal liver cells have a severely impaired capacity to repopulate the erythroid and myeloid compartments. Our analysis reveals the absence of $S p 3^{-1-}$ myeloid cells at all peripheral sites investigated. In the bone marrow, we found that $S p 3^{-1-}$ cells fail to contribute to the erythroid/myeloid progenitor pool. Since these cells are contributing quite efficiently to the lymphoid system in the same animals, we conclude that Sp3 plays an important role in the development of erythroid/myeloid progenitors. Possibly, Sp3 acts at the early level of the common progenitors to the erythroid and myeloid lineages. Clearly, more experiments are needed to further define the function of Sp3 in myeloid development. In this regard, it is of interest to note that mice deficient for the Sp/XKLF family member BKLF develop a myeloproliferative disorder, ${ }^{46}$ raising the possibility of antagonistic functions of $\mathrm{Sp} 3$ and BKLF in myelopoiesis.

\section{Conclusions}

Here, we describe the effect of the Sp3-null mutation on hematopoiesis. Our findings, in particular the in vivo transplantation assay, showed that the absence of Sp3 results in cell-autonomous differentiation defects in the erythroid and myeloid cell lineage. Sp/XKLF factors share 3 highly conserved DNA-binding zinc fingers, and most hematopoietic cell populations express multiple members of the Sp/XKLF family. In conjunction with the phenotypes of the Sp/XKLF knockouts for which hematopoietic defects have been reported in this paper and elsewhere, $, 8,11,13,47$ it can be anticipated that Sp/XKLF factors have overlapping functions in hematopoietic cells. We are currently generating compound mutants to address this issue.

\section{Acknowledgments}

We thank H. Dronk from the Erasmus MC animal facility and G. Dingjan from Erasmus MC Department of Immunology, Rotterdam, The Netherlands, for their assistance.

\section{References}

1. Philipsen S, Suske G. A tale of three fingers: the family of mammalian Sp/XKLF transcription factors. Nucleic Acids Res. 1999;27:2991-3000

2. Costa MW, Atchison ML. Identification of an Spllike element within the immunoglobulin kappa 3' enhancer necessary for maximal enhancer activity. Biochemistry. 1996;35:8662-8669.

3. Rotheneder H, Geymayer S, Haidweger E. Transcription factors of the Sp1 family: interaction with $\mathrm{E} 2 \mathrm{~F}$ and regulation of the murine thymidine $\mathrm{ki}-$ nase promoter. J Mol Biol. 1999;293:1005-1015.

4. Hirano F, Tanaka $\mathrm{H}$, Hirano $\mathrm{Y}$, et al. Functional interference of Sp1 and NF-kappaB through the same DNA binding site. Mol Cell Biol. 1998;18: 1266-1274.

5. Merika M, Orkin SH. Functional synergy and physical interactions of the erythroid transcription factor GATA-1 with the Kruppel family proteins Sp1 and EKLF. Mol Cell Biol. 1995;15: 2437-2447

6. Birnbaum MJ, van Wijnen AJ, Odgren PR, et al. Sp1 trans-activation of cell cycle regulated promoters is selectively repressed by Sp3. Biochemistry. 1995;34:16503-16508.

7. Dennig J, Hagen G, Beato M, Suske G. Members of the Sp transcription factor family control transcription from the uteroglobin promoter. J Biol Chem. 1995;270:12737-12744.

8. Perkins AC, Sharpe AH, Orkin SH. Lethal betathalassaemia in mice lacking the erythroid CACCC-transcription factor EKLF. Nature. 1995; 375:318-322.
9. Nuez B, Michalovich D, Bygrave A, Ploemacher $R$, Grosveld F. Defective haematopoiesis in fetal liver resulting from inactivation of the EKLF gene. Nature. 1995;375:316-318

10. Gillemans N, Tewari R, Lindeboom F, et al. Altered DNA-binding specificity mutants of EKLF and $\mathrm{Sp} 1$ show that EKLF is an activator of the beta-globin locus control region in vivo. Genes Dev. 1998;12:2863-2873.

11. Perkins AC, Yang $H$, Crossley PM, Fujiwara $Y$ Orkin SH. Deficiency of the CACC-element binding protein, BKLF, leads to a progressive myeloproliferative diease and impaired expression of SHP-1 [abstract]. Blood. 1997;90(suppl 1):575a.

12. Kuo CT, Veselits ML, Barton KP, Lu MM, Clendenin C, Leiden JM. The LKLF transcription factor is 
required for normal tunica media formation and blood vessel stabilization during murine embryogenesis. Genes Dev. 1997;11:2996-3006.

13. Kuo CT, Veselits ML, Leiden JM. LKLF: a transcriptional regulator of single-positive $T$ cell quiescence and survival. Science. 1997;277:19861990.

14. Marin M, Karis A, Visser P, Grosveld F, Philipsen S. Transcription factor Sp1 is essential for early embryonic development but dispensable for cell growth and differentiation. Cell. 1997;89:619-628.

15. Bouwman P, Gollner H, Elsasser HP, et al. Transcription factor $\mathrm{Sp} 3$ is essential for post-natal survival and late tooth development. EMBO J. 2000 19:655-661.

16. Gollner H, Dani C, Phillips B, Philipsen S, Suske $\mathrm{G}$. Impaired ossification in mice lacking the transcription factor Sp3. Mech Dev. 2001;106:77-83.

17. Nguyen-Tran VT, Kubalak SW, Minamisawa S, et al. A novel genetic pathway for sudden cardiac death via defects in the transition between ventricular and conduction system cell lineages. Cell. 2000;102:671-682.

18. Gollner H, Bouwman P, Mangold M, et al. Complex phenotype of mice homozygous for a null mutation in the Sp4 transcription factor gene. Genes Cells. 2001;6:689-697.

19. Kingsley $\mathrm{C}$, Winoto $\mathrm{A}$. Cloning of GT box-binding proteins: a novel Sp1 multigene family regulating T-cell receptor gene expression. Mol Cell Biol. 1992;12:4251-4261.

20. Sikes ML, Gomez RJ, Song J, Oltz EM. A developmental stage-specific promoter directs germline transcription of $\mathrm{D}$ beta $\mathrm{J}$ beta gene segments in precursor T lymphocytes. J Immunol. 1998; 161:1399-1405

21. Lin JX, Leonard WJ. The immediate-early gene product Egr-1 regulates the human interleukin-2 receptor beta-chain promoter through noncanonical Egr and Sp1 binding sites. Mol Cell Biol. 1997; 17:3714-3722

22. Malone CS, Patrone L, Wall R. An essential octamer motif in the mb-1 (Igalpha) promoter. Mol Immunol. 2000;37:321-328.

23. Malone CS, Omori SA, Wall R. Silencer elements controlling the B29 (Igbeta) promoter are neither promoter- nor cell-type-specific. Proc Natl Acad Sci U S A. 1997;94:12314-12319.
24. Himmelmann A, Thevenin C, Harrison K, Kehrl $\mathrm{JH}$. Analysis of the Bruton's tyrosine kinase gene promoter reveals critical PU.1 and SP1 sites. Blood. 1996;87:1036-1044

25. Rohrer J, Conley ME. Transcriptional regulatory elements within the first intron of Bruton's tyrosine kinase. Blood. 1998;91:214-221.

26. Friedman AD. Transcriptional regulation of granulocyte and monocyte development. Oncogene. 2002;21:3377-3390

27. Hendriks RW, de Bruijn MF, Maas A, Dingjan GM, Karis A, Grosveld F. Inactivation of Btk by insertion of lacZ reveals defects in $B$ cell development only past the pre-B cell stage. EMBO J. 1996;15: 4862-4872.

28. de Bruijn MF, Slieker WA, van der Loo JC, Voerman JS, van Ewijk W, Leenen PJ. Distinct mouse bone marrow macrophage precursors identified by differential expression of ER-MP12 and ERMP20 antigens. Eur J Immunol. 1994;24:22792284.

29. Rolink A, Streb M, Melchers F. The kappa/lambda ratio in surface immunoglobulin molecules on $B$ lymphocytes differentiating from $\mathrm{DHJH}$-rearranged murine pre-B cell clones in vitro. Eur $\mathrm{J} \mathrm{Im-}$ munol. 1991;21:2895-2898.

30. Dingjan GM, Middendorp S, Dahlenborg K, Maas A, Grosveld F, Hendriks RW. Bruton's tyrosine kinase regulates the activation of gene rearrangements at the lambda light chain locus in precursor B cells in the mouse. J Exp Med. 2001;193:1169 1178.

31. Wong PM, Chung SW, Chui DH, Eaves CJ. Properties of the earliest clonogenic hemopoietic precursors to appear in the developing murine yolk sac. Proc Natl Acad Sci U S A. 1986;83:38513854.

32. Whyatt $D$, Lindeboom $F$, Karis $A$, et al. An intrinsic but cell-nonautonomous defect in GATA-1-overexpressing mouse erythroid cells. Nature. 2000 406:519-524.

33. Beug $\mathrm{H}$, Palmieri $\mathrm{S}$, Freudenstein $\mathrm{C}$, Zentgraf $\mathrm{H}$ Graf T. Hormone-dependent terminal differentiation in vitro of chicken erythroleukemia cells transformed by ts mutants of avian erythroblastosis virus. Cell. 1982;28:907-919.

34. Muller AM, Dzierzak EA. ES cells have only a limited lymphopoietic potential after adoptive trans- fer into mouse recipients. Development. 1993; 118:1343-1351.

35. Muller AM, Medvinsky A, Strouboulis J, Grosveld F, Dzierzak E. Development of hematopoietic stem cell activity in the mouse embryo. Immunity. 1994;1:291-301.

36. Singer A. New perspectives on a developmental dilemma: the kinetic signaling model and the importance of signal duration for the CD4/CD8 lineage decision. Curr Opin Immunol. 2002;14:207215

37. Lucas B, Germain RN. Unexpectedly complex regulation of $\mathrm{CD} 4 / \mathrm{CD} 8$ coreceptor expression supports a revised model for CD4+CD8 + thymocyte differentiation. Immunity. 1996;5:461-477.

38. Russell ES, Bernstein SE. Blood and blood formation. In: Roscoe B. Jackson Memorial Laboratory. EL Green, ed. Biology of the Laboratory Mouse, by the staff of the Jackson Laboratory. 2nd ed. New York, NY: McGraw-Hill; 1966:351372.

39. Dutton RW, Bradley LM, Swain SL. T cell memory. Annu Rev Immunol. 1998;16:201-223.

40. Wijgerde M, Gribnau J, Trimborn T, et al. The role of EKLF in human beta-globin gene competition. Genes Dev. 1996;10:2894-2902.

41. Cai Z, de Bruijn M, Ma X, et al. Haploinsufficiency of AML1 affects the temporal and spatial generation of hematopoietic stem cells in the mouse embryo. Immunity. 2000;13:423-431.

42. Strouboulis J, Dillon N, Grosveld F. Developmental regulation of a complete $70-\mathrm{kb}$ human betaglobin locus in transgenic mice. Genes Dev. 1992;6:1857-1864.

43. Hagen G, Muller S, Beato M, Suske G. Sp1-mediated transcriptional activation is repressed by Sp3. EMBO J. 1994;13:3843-3851.

44. Kondo M, Weissman IL, Akashi K. Identification of clonogenic common lymphoid progenitors in mouse bone marrow. Cell. 1997;91:661-672.

45. Katsura Y. Redefinition of lymphoid progenitors. Nat Rev Immunol. 2002;2:127-132.

46. Turner J, Crossley M. Basic Kruppel-like factor functions within a network of interacting haematopoietic transcription factors. Int J Biochem Cell Biol. 1999;31:1169-1174.

47. Wani MA, Means RT Jr, Lingrel JB. Loss of LKLF function results in embryonic lethality in mice. Transgenic Res. 1998;7:229-238. 